\title{
A Thermodynamic Metric for Assessing Sustainable Use of Natural Resources
}

\author{
S. Kjelstrup ${ }^{1, *}$, J. Dewulf ${ }^{2,3}$ and B. Nordén ${ }^{4}$ \\ ${ }^{1}$ Norwegian University of Science and Technology, Høgskoleringen 5, 7491-Trondheim, Norway \\ ${ }^{2}$ European Commission (EC) - Joint Research Centre, Ispra, Italy \\ ${ }^{3}$ Ghent University, Ghent, Belgium \\ ${ }^{3}$ Chalmers University of Technology, Gothenborg, Sweden \\ E-mail: $\underline{1 \text { signe.kjelstrup@ntnu.no }}$
}

Received 28 December 2014, Accepted 14 January 2015

\begin{abstract}
A thermodynamic metric is proposed to supplement existing scales in the assessment of the way we use our natural resources. This metric has the advantage of being absolute and independent of economy, suitable for comparison of technologies, and can be used at molecular level as well as process-units and systems levels. It measures loss of useful work (exergy) in cradle-to-grave or complete recycling systems in terms of generalized friction or entropy production and may deliver realistic targets for process operations. This absolute scale can be useful also for international legislation and to foster a development in direction of more sustainable technologies. In an extended perspective, the presented approach may form a universal basis for analysis and development of national economies and policies regarding industry, engineering and environment. This may give new opportunities to put political resource discussions on a solid objective footing.
\end{abstract}

\section{Keywords: Thermodynamic efficiency; resource efficiency; exergy in legislation.}

\section{Introduction}

We know now that the natural resource situation of the world [1] is tightly linked to a changing climate and to peoples' welfare. The joint European research programme, Horizon 2020, has therefore made "resource efficient Europe" into one of seven flagship priority areas. According to the European Energy Efficiency Directive (EED) of 2012/27/EU [2], the aim is to reduce the energy use by an average of $20 \%$ within 2020 in all sectors combined. At the same time, resource criticality has received growing attention, bringing awareness about the vulnerability of modern society in terms of a high degree of dependency on natural resources. Supply risks, environmental consequences and vulnerability to supply of raw materials are discussed in important works, see e.g. Graedel et al. [3] and Valero and Valero [4].

The policy targets are ambitious, but can we hope to succeed? The number $20 \%$ seems to have been set rather arbitrarily, without any detailed analyses of consequences, or of potential further improvements. Activities related to better resource efficiencies are still rather end-of-pipe driven than based on outcome of an upfront design. Clearly, due to the great complexity it is not enough to consider single process units. In order to be meaningful, one has to consider all phases and aspects of the life cycle of a system in a total context. Furthermore, current efforts are not well rooted in analyses or legislation. Although legislation might strive for more renewable energy and products, it frequently does not account sufficiently for efficient and environmentally friendly production. There are even examples of profligate environmental legislation that contribute to worse resource efficiency, as we shall see.

The present work will propose that more attention be given to metrics that can help reach targets set, from a physical and engineering point of view. Methods are in principle there, but need to be systematically implemented: this task is not only a responsibility of the scientists, but lies to a great extent in the hands of the politicians. We therefore, hope to contribute to paving the ground for a common systematic effort and effective legislation, for work that aims to reduce global warming by increasing the global energy efficiency. Certain existing tools are namely as of yet not used in a systematic manner but could, if applied, considerably improve the situation. We propose here to foster a development that can lead to the establishment of a universal scale for Europe (and the world), for common use to measure energy and material conversion. The scale that we suggest is provided by the laws of thermodynamics and is thereby absolute and objective. It has been advocated by certain scientific communities, however, it is not yet in practical use.

The present work will provide a definition of resource efficiency improvement derived from the laws of nature. Presently, energy efficiency is defined by the EED in economic terms only. According to EED, an energy efficiency variation can be measured by recording the energy input before and after a certain change has been introduced to a process, keeping the same level of economic activity or service. This definition is useful in economic contexts, but has several flaws in an environmental and physical context. It offers little systematic help to improve a 
technology beyond the "best practice", because it does not offer insight into what is achievable. It can clearly foster developments of cheaper solutions, but these are not necessarily more resource efficient. By using an economybased definition alone, the society will be missing out on a number of benefits that the metric we suggest, can give. Such a concern has been articulated already by scientists in the field, as an Appeal to an EU and UN meeting at the Joint European Thermodynamics Conference in 2013[5]. Our paper can be regarded as a strong support of that appeal.

Physical laws are rarely used in policy contexts, despite the early proposal of Georgescu-Roegen [6]. The pressing problems associated with drained resources and with a changing climate are now, however, asking for an interdisciplinary, holistic approach.

\section{An Area of Resource Engineering}

Already from the definition of sustainability proposed by Brundtland to the United Nations in 1987, it is clear that a sustainable development can only be obtained if it is approached in a multidisciplinary way. The engineering part, which relies on physical laws, has a key function in this context: it provides the technology that delivers goods and services. Technology and society share physical boundaries with the environment. Energy and material resources are withdrawn from the natural environment to fuel various activities, returning emissions to the environment.

In the early 1970 s society became aware of various undesirable effects of the industrial activity. One example was the discovery of stratospheric ozone depletion (Molina and Rowland [7]) where chlorofluorocarbon molecules were destroyed by radiation, releasing chlorine radicals which next destroyed millions of ozone molecules. Society then drove political decision-makers to take action at a number of levels. European regulation forced industry to come up with clean-up technology, which was rapidly implemented in Europe in the 1970s - mid 1990s: wastewater treatment, waste-gas cleaning and solid-waste handling. As a consequence, numerous environmental effects are under far better control today than before 1970 , including the emission of a number of ozone depletion precursors, air and water acidification, toxic emissions etc. But the global warming problems have by and large remained unsolved.

The insight came that end-of-pipe solutions brought not only economic costs, but required extra energy and materials. Since the mid-1990s, and with the growing awareness of the greenhouse effect, technology design gradually evolved away from clean-up towards clean technology. This approach is obviously more holistic than the clean-up approach. Indeed, it means a new conceptual design that can make technology more environmentally compatible. It starts from a cradle-to-grave approach of the full production and consumption chain, considering the resource intake pattern, the production technology, the product-service relation, and the end-of-life fate of the product. Ultimately, all resources should be transformed into useful products with no net emissions generated, eventually making clean-up technology unnecessary. In this sense, after an era of environmental end-of-pipe engineering, we are facing an era of resource engineering [8].

\section{Clean Technology: Conceptual Developments and the Need for Metrics}

The reconsideration of technology development led to new concepts in the 1990s. The most prominent examples are Industrial Ecology (e.g. T.E. Graedel, Yale), the 12 principles of Green Chemistry and the 12 principles of Green Engineering (P. Anastas, formerly at US EPA). These initiatives proposed new specific technologies, e.g. biobased technology, but also new ways of organizing the industrial society as a whole. Dewulf et al.[9] proposed the Closed Cycle Approach for an ideal organisation of the society, sustainable and compatible with the environment (Figure 1). The society and industry combined, i.e. the "technosphere", should make use of the continuous delivery of renewable resources available in the ecosphere. This means also to take advantage of the continuous supply of energy from the sun, and to make use of the photosynthesis in the conversion of low quality products like carbon dioxide into renewable materials. In this ideal scenario, emissions feed the ecosphere with low-quality products that do not affect it.

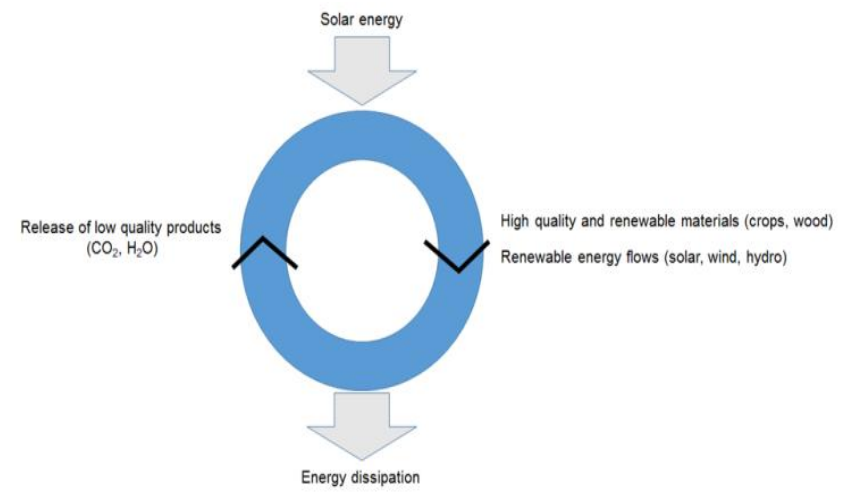

Figure 1. A solar driven cycle: Economy of the technosphere, modified after Dewulf et al. [9]

But proper resource engineering does not only mean a change in the intake pattern, it also means to choose smart paths after the in-take of resources. Efficient energy and mass conversion is of utmost importance at all levels: at the molecular level, at process level and at the product's life cycle level. Jos Delbeke, Deputy Director-General of DG Environment of the European Commission, gave a clear statement on this issue at the Innovation for Sustainable Production conference, held in Brugges in April 2010: the majority of opportunities for better services to the community (in combination with lower carbon footprints) are not found in alternative power sources, but rather in the improved resource utilization efficiencies.

The ways our industrial society directs various flows between the production processes and the consumption activities, are clearly strongly affecting the resource efficiency. Definitely, by applying a global approach, we can take advantage, from the industrial ecology theory, to find opportunities to far better utilize by-products and waste as substitutes for virgin energy and material resources [10]. Nevertheless, the question arises, to what extent technology evolution and innovation indeed contributes to a cleaner and more sustainable production. One may also wonder 
whether limits exist for what is achievable. The need for metrics becomes then central.

Classical life cycle assessment (LCA) evolved in the 1990s in order to assess emissions and their impacts. Currently, the LCA research community also faces the challenge to address social and economic impacts of production and consumption systems [11]. However, LCA did never primarily focus on the resource intake pattern or on the overall efficiency of the production and consumption chain; neither did it provide improvement potentials, as goals and policy targets were mainly determined from a technical point of view.

Engineers need and use metrics for optimizing industry processes, but the society as a whole can also take advantage of metrics to obtain sound judgments in environmental context. In order to assess environmental sustainability and proper resource use, physical metrics need to be developed, for efficient use of energy and material resources on all physical scales, from the molecular processes to the overall supply chain.

\section{Developing Metrics}

In the ideal situation, we have a metric that can steer the development of our industrial society in direction of a more sustainable use of natural resources. In their effort to achieve this, economists typically start from the resource productivity, i.e. the economic value per amount of resource intake, see e.g. the Resource efficiency scoreboard of Eurostat [12]. Economic metrics are quite obvious in our open market economy and are inherently considered in our modern society. The definition used in the EU documents and referred to in the Introduction, means that a reduction in the original energy costs in monetary units for a given service from $S\left(\mathrm{E}_{1}\right)$ to $S\left(E_{2}\right)$ gives an improvement factor

$$
\zeta=\frac{S\left(E_{1}\right)-S\left(E_{2}\right)}{S\left(E_{1}\right)}
$$

The ratio increases as $S\left(E_{2}\right)$ becomes smaller. But costs and energy prices vary widely with time and location in the world, and the possibility to improve an energy service depends on the starting point, the energy input $E_{l}$ and $S\left(E_{l}\right)$. This metric can, thus, not give any absolute yardstick for technology development.

To see this better, take as an example a (nearly) reversible engine, the Stirling motor, a friction-free piston moved in a cylinder by air of changing temperature. The frictional losses of this machine engine are so small, that they cannot be practically improved: we are already at a technological limit of performance. This machine can only be improved in economic terms by replacing existing materials with cheaper ones.

Within the engineering and environmental science community, the resource efficiency has been interpreted in many ways, which can be stripped down to mainly two approaches, see Huysman et al. [13]. In the first one, benefits (outputs) are related to inventoried flows (inputs). These are frequently characterized in physical quantities, e.g. kWh of energy supplied per tonnes of fuels as input; but can in principle also be monetarized. In the second type, environmental scientists relate benefits to environmental consequences, e.g. the contribution to global warming per capita for transport. However, neither of these efficiencies offer upper limits and do therefore not bring insight into what room may be left for improvement.

This all could change if emphasis is made on Thermodynamics and in particular by including consequences of the Second Law of Thermodynamics. The "exergy" concept, as explained below, can bring the physical efficiency onto a 0 to $100 \%$ scale. Exergy is simply expressed the energy that is available for work [14]. The fundamentals of thermodynamics were established already in the 1800s. Einstein said that they made a deep impression upon him; he was convinced that they can never be overthrown. There is an active community of scientists and engineers who are using the method today [3-5]. However, it is only during the past few years that the exergy concept has gained a more widespread interest beyond analysis of industrial systems. The concept reveals resource consumption patterns and resource efficiencies in the physical sense, see Dewulf et al. [15], and it can be well incorporated into LCA $[16,17]$. Within the thermodynamic realm, there are two ways to address energy and mass efficiency: by the first law of thermodynamics alone, or by combining the first and the second laws.

The first law of thermodynamics states that no energy and mass can disappear or be created in any process. According to the first law, the efficiency is defined by the ratio of work, $W$, obtained from heat added, $Q$, to a process. The definition does not specify the temperature at which heat enters the system. This gives it a severe draw-back when evaluating processes that are wasting heat, like the large electrometallurgical industry, as we know that heat at high temperature can do a different amount of work than heat at low temperature (as already noticed in the development of steam engines). The formula is, furthermore, not useful for processes that run on other energies than heat. The energy conversion in salt power plants, for instance, is provided by the energy of mixing of seawater and river water, and this process takes place without significant heat changes. In a salt power plant, the first law efficiency would be infinite. This of course makes the definition unsuitable, when we want to compare different technologies, including salt power plants, or set limits of technology performance.

With the use of both laws of thermodynamics, these deficiencies can be amended. The second law of thermodynamics postulates that any real process is associated with friction and thereby generates entropy. This means that the quality of energy will always decrease during conversion of energy from one form to another. The energy quality that varies with the temperature can be expressed as "useful energy" in terms of the exergy concept: it is the maximum amount of work that can be obtained from a set of materials, taking into account the state of the surroundings. The degradation of energy is given by the entropy generated by a process. If we multiply the entropy production with the temperature of the surroundings, $T_{0}$, we obtain the destructed exergy, see Eq. (3) below.

The use of resources in technology and society contribute to deterioration of exergy resources in various ways. If we strive for sustainable production and consumption, the entropy production should be as low as possible. Products and wastes can be potential resources as long as they maintain their exergy content. 
Quite unique is that a thermodynamic analysis, and hence an exergy analysis can be performed at whatever scale is needed, always accounting for whatever physical input or output: mass and energy flows, kinetic energy, potential energy, heat and radiation. Exergy analysis [3,4, 14-17] can be used to evaluate any process unit or process cycle to map the exact locations of efficiency losses, and to assign a value to mineral resources or other resources (e.g. clean water). In a work-producing process, the exergy efficiency can be expressed as the real work obtained, $W$, relative to the maximum work obtainable in an ideal process, $W_{\text {ideal }}$. The simplest definition is

$\eta=W / W_{\text {ideal }}$

meaning that an ideal (reversible) machine has unit efficiency. A deviation from this value measures the distance from reversible operation.

A simple example is a battery. The ideal work is the work obtained with the electromotive force (the open circuit potential). The real work is obtained from the reduced battery voltage as current is drawn. In the end, when the battery is flat, its efficiency is zero. The work and ideal work are absolutes, not subject to any discussion, so the efficiency can be said to be "objective" in this sense. It can thus serve as a yardstick, suitable for comparing different technologies.

Not only efficiency is important, however, also the absolute value of the entropy production matters. For workproducing machines, the difference is the lost work $W_{\text {lost }}$

$W_{\text {lost }}=W_{\text {ideal }}-W$

For a work-consuming process $W_{\text {lost }}=W-W_{\text {ideal }}$ and the efficiency is the inverse of Eq. (2). The degradation of useful energy in terms of lost work (destructed exergy) is equal to the entropy production $\left(d S_{\mathrm{irr}} / d t\right)$ times the temperature of the surroundings, $T_{0}$ :

$W_{\text {lost }}=T_{0}\left(d S_{i r r} / d t\right)$

In these equations $W$ has dimension $\mathrm{J} / \mathrm{s}$. The system boundaries must be set to include all downstream processes which can utilize exergy flows.

Take the example of distillation to illustrate the use of these formulae. Distillation is a process that separates components of a mixture by boiling it. For example, crude oil is refined this way to produce various hydrocarbon fuels. Distillation consumes about $7 \%$ of all power produced in US [18]. The adiabatic column is common. This is a tower with trays for liquid-vapor contact (see Figure 2) which is heated only from the bottom tray.

The exergy efficiency of adiabatic distillation is rather low (around 30\%), but can be increased significantly by minimization of destructed exergy (entropy production). According to a group of 10 scientists at the ECOS meeting series, meeting in Guanajuato in Mexico in 2004, the efficiency of present day's adiabatic distillation techniques can be doubled by implementing heat integration techniques [19-22]. This means to change the column design, for instance in the way pictured in Fig. 3, where one long column has been split in two parts. The two types of distillation pictured in Fig.1 and 3, were evaluated by Røsjorde et al. [20] for benzene-toluene separation, and are illustrated in Table 2. The table shows that it is possible to obtain the same product with $60 \%$ of the original exergy loss (compare 673 to $1025 \mathrm{kWh}$ ) and smaller exergy input (935 vs. $1492 \mathrm{kWh}$ ). Required is a system redesign.

The joint statement of the scientists cited above is a purely thermodynamic one. It gives a message on the status of one technology and the potential for improvement from a physical perspective. Such statements can help choose between routes forward as other measures are added. Exergy analysis can contribute in this way to a (worldwide) effort to produce with smaller amounts of destructed exergy, evaluate system loops, etc. This supplements what economically based definitions can do.

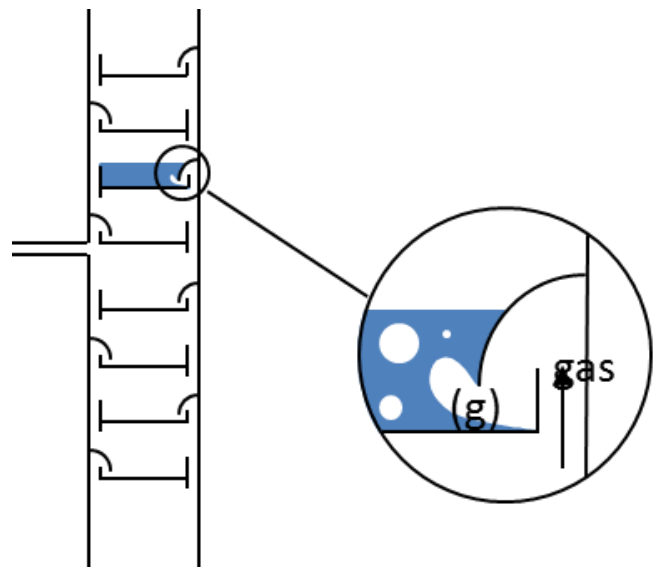

Figure 2. Schematic illustration of an adiabatic distillation column, where vapor is rising across trays of liquid (colored blue), and liquid is falling down. If heat can be added/ taken away where it is needed, the separation will take place with smaller destructed exergy (smaller entropy production)..

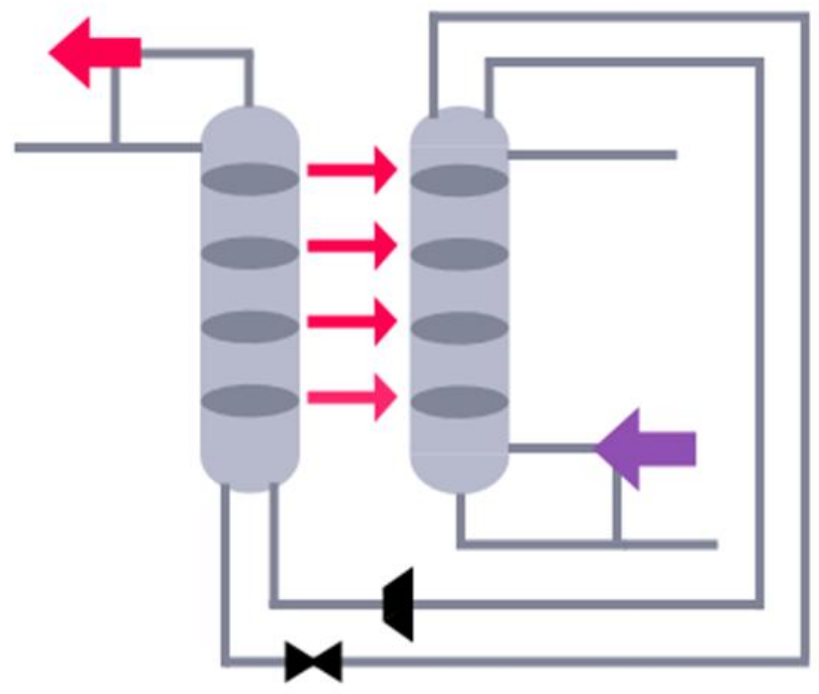

Figure 3. A heat integrated distillation column (schematically). Heat given off in the upper section is delivered directly to the lower section. Compressor work is needed to maintain a higher pressure in this part, in order to keep up the separation work. 
The equations presented do not capture all aspects on the wide definition of the concept "sustainability" used by Brundtland. Medical aspects of wastes, like toxic effects on human health, can obviously not be covered. Wider social and political challenges and trade-offs between environmental, social and economic objectives of sustainability are not addressed by an exergy efficiency measure alone, but the exergy efficiency can be one of several indicators in this trade-off. Nevertheless, as exergy analysis becomes more and more sophisticated [4, 8,9,17, 23], we may hope to cover many of the aspects of sustainability, like those related to scarcity of natural resources (water, minerals, fossile fuels) or their depletion, dissipation, and contamination. This and the fact that emission related indicators are correlated for many products in a life-cycle perspective [24], provide good reasons to claim that the efficiency (4), when applied to life cycles, is not only a measure of the energy conversion efficiency, but also a measure of certain aspects of sustainability.

In summary, one can obtain a scale which is

- An objective measuring scale, independent of costs and prices

- A quantitative, absolute measure which can be used to compare technologies

- A target for optimization: Minimum entropy production means maximum efficiency

- A tool that can be used to relate macro-scale performance to events at the micro-scale

Table 1. The exergy content of work and heat flows during distillation of benzene-toluene in a column under adiabatic conditions or with heat integration in the various column parts (HIDIC) after Røsjorde et al.[20]All numbers refer to the feed flow $100 \mathrm{~mol} / \mathrm{s}$. For other specifications, see ref.20.

\begin{tabular}{|c|c|c|}
\hline $\begin{array}{c}\text { Exergy added/ } \\
\text { kWh } \\
\text { Column part }\end{array}$ & $\begin{array}{c}\text { Adiabatic } \\
\text { column }\end{array}$ & $\begin{array}{c}\text { HIDIC } \\
\text { column }\end{array}$ \\
\hline Reboiler & 1492 & 105 \\
\hline Condenser & -467 & -225 \\
\hline Compressor & 0 & 831 \\
\hline $\begin{array}{c}\text { Column heat } \\
\text { exchange }\end{array}$ & 0 & -37 \\
\hline $\begin{array}{c}\text { Sum=Destructed } \\
\text { exergy }\end{array}$ & 1025 & 673 \\
\hline
\end{tabular}

The two last bullet points need further comments. The word "optimization" in the third bullet point is meant in the mathematical sense. The society does not have zero production as alternative. We want a certain production level, and it is not possible to produce without any exergy losses. These losses can however be minimized with the technique of constrained minimization [19-21]. This was done to obtain the data in the right hand side column of Table 1. A production state with minimum entropy production, obtained in this manner, may not be realizable in practice, because special materials are needed (or because the new design is unrealistic). But the state and knowledge of the state will provide an ideal limit for the given technology, a limit which is more realistic than the reversible limit. In the reversible limit contact areas are huge, and processes are infinitely slow. The potential improvement factor was expressed by the ratio (exergy loss- un-avoidable exergy loss)/exergy loss [22]. Other more specific factors can be useful for trend analysis $[9,17]$.

Behind the fourth bullet point is the fact that the exergy efficiency has a link to the field of non-equilibrium thermodynamics [21]. This link can be used to gain understanding of the losses at the molecular level. Take again as an example, the process of distillation pictured in Fig.2. In order to be able to direct the precise amount of heat to each gas-liquid interface where evaporation or condensation take place, one must have first-hand knowledge on the resistance of the liquid-vapour interface to heat and mass transfer. Such resistances can be obtained from experiments or molecular simulations, defined according to non-equilibrium thermodynamics, to properly take into account microscopic reversibility, but no systematic data for the interface are yet available. Knowledge of the entropy production and its origin can open the door for systematic improvements of the process. In most of the cases, the clue to improvements lies in the understanding and control of the entropy production.

\section{A formula to Assess Sustainable Use of Natural \\ Resources}

The advantage of formula (2) and its derivatives in the measurement of the efficiency of resource use, is its versatility. It can be used on a micro-scale as well as a macro-scale level of analysis. On the macro-scale, it can be used for single process units and process cycles in the industry. On this scale, it can also be used, for example, to measure the value of untapped mines and ores through the exergy costs needed to restore these ores [4,23]. The mineral depletion in the world is thus strongly associated with exergy efficiency issues.

Concerning the process level, the US department of energy presented a report, identifying process inefficiencies in the U.S. chemical industry. It was revealed that the amount of destructed exergy, hence lost physical resources, was ranging from about 1 Tbtu/year in crystallization process to 172 and $690 \mathrm{Tbtu} / \mathrm{yr}$ for distillation and heat/electrical/steam energy respectively [25]. In other words, more than say 5000 big wind mills of $5 \mathrm{MW}$ are necessary to provide the immediately dissipated power for the two latter processes in the U.S. chemical industry. For the US industries, Ayres et al. [26] calculated the loss as 65 and $71 \%$, for the organic and inorganic chemical industries, respectively, this being the same order of magnitude as for the US industry as a whole $(62.4 \%)$. Losses have also been calculated at a national level, revealing that typically more than $85 \%$ of the resources are dissipated. This is illustrated in Figure 3 the UK in 2010: The figure shows that 192.4 Mtoe of the 222.9 Mtoe primary exergy is lost. Similar diagrams have been obtained for other countries, e.g. Italy, Sweden, and Norway. Brockway et al. [27] analyzed the trends of losses at the national level for the US and UK between 1960 and 2010. While the US losses remained stable at about $89 \%$, the UK efficiency improved losses 
from 91 to $85 \%$. They speculated that the stagnating US national exergy efficiency was mimicking the 'efficiency dilution' effect: lower efficiency processes (airconditioning has risen from 10 to $20 \%$ of electricity end use) outweigh efficiency gains elsewhere.

\section{Bringing Exergy as a Metric for Physical Resource Efficiency into Legislation?}

Figure 4 is typical for countries where such data exist. It shows the types of natural resources that we rely on and illustrates our strong dependence on non-renewables. This dependence will continue for a long time despite several national policy programs to promote the use of renewable resources. The slow growth of renewable technologies may be explained by limited cost effectiveness, but also unanticipated effects hamper the development, e.g. the food and energy competition for land. In some cases, renewablebased power has shown to even generate more greenhouse gases than non-renewable sources over its life cycle. Policy makers are thus becoming more and more aware of the importance of life cycle assessments, in particular if it comes to emissions. As an illustration, Swiss authorities made an amendment in 2008 on the requirement to prove a positive global ecological effect of biofuels, stating that they must generate $40 \%$ less greenhouse gases than conventional gasoline, from production to use [28].

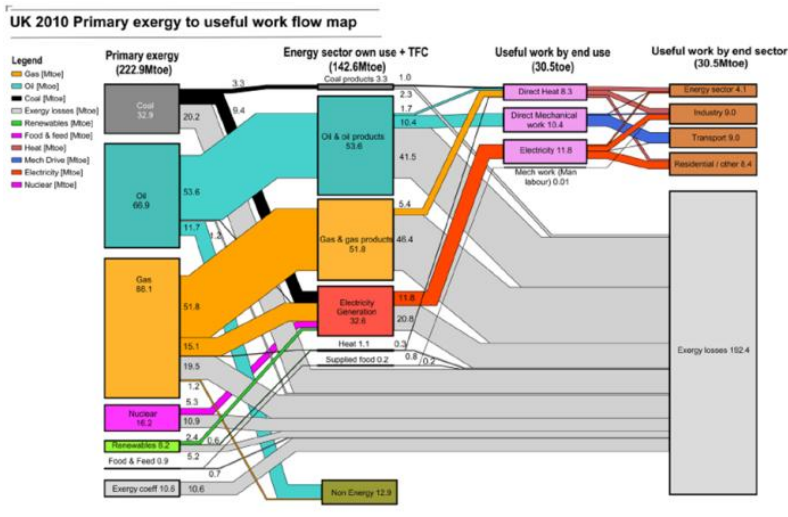

Figure 4. UK exergy to useful work and losses chart (according to Brockway et al [27]5) Copyright permission by ACS Author Choice CC-BY usage agreement.

Although legislation might be striving for more renewable, efficient and environmentally friendly production and consumption, resource balances and resource efficiencies are not yet accounted for in a life cycle perspective. These balances are not used in practice whether they rely on exergy or other metrics. There are even examples of profligate environmental legislation that contribute to lower resource efficiency. By making use of exergy as a tool for evaluation of the physical resource efficiency of recycling systems, Ignatenko et al.[29] investigated car recycling scenarios as a result of recycling/recovery targets for end-of-life vehicles (Directive 2000/53/EC). They demonstrated that the recovery of materials, especially of lower grade and quality, was associated with significant additional primary resources.

Nevertheless, the above examples show that a development of research in this field will help develop robust and safe ways to measure progress from a resource perspective. A start has already been made to incorporate exergy as an indicator in legislation. The state (Canton) of Geneva has implemented exergy indicators at the installation level in procedures for attribution of building permits [28].

\section{Conclusion}

The availability of a common scale to measure the physical resource efficiency of any process will likely enhance a desirable development towards a more resourceefficient, climate friendly world. A universal scale is needed in order to get an objective, systematic approach to problems associated with a very complex global situation both regarding the manifolds of true physical systems involved as well as the various political systems, because of their respective enormous diversities. We have proposed here that the second law of thermodynamics be used to gauge the energy efficiency in such a scale. We have explained how such an efficiency scale can serve as a resource efficiency instrument, to monitor sustainability of processes and to set targets. To introduce the second law of thermodynamics in efficiency considerations, will contribute significantly to realizations of the aims of Horizon 2020, as well as of national research programs.

As a step towards a systematic use of the objective scale, we propose to standardly use exergy analysis in all processes, in the industry, in the public and governmental sectors, in power production or power consuming units. This gives an overview of the state of use of our energy and material resources. An international Exergy Panel, appointed to collaborate with the international climate panel, could, for example, be given an assignment to survey and publish a data basis of such information. The overview is needed before optimizations can be done. It can be advantageous for the governmental sector, in their effort to set good targets and limits for performance. In parallel, the systems analysis should continue, including applying exergy to analyzing life-cycle perspectives. Likewise, it would allow us to address the various molecular phenomena that lead to excess entropy production, and in this way also understand the mechanistic origins of energy loss at a microscopic level. Doing this, we will be able to develop more realistic targets for the use of our valuable material and energy resources, and foster a development in direction of more sustainable technologies. There are presently 35000 members of the Energy Efficiency in Industrial Processes initiative, EEIP, launched at the European Commission, April 2011, who exchange information on best practices. These can make a difference, given more tools and a concerted action.

\section{Nomenclature}

$\mathrm{S}(\mathrm{E}) \quad$ Monetary cost of (energy) service $\mathrm{E}$ in $\mathrm{J}$

dS/dt Entropy production of system, J/Ks

$\mathrm{T} \quad$ Absolute temperature, $\mathrm{K}$

W Work per unit of time (power), $\mathrm{J} / \mathrm{s}$

Wideal Ideal work per unit of time, $\mathrm{J} / \mathrm{s}$

Wlost Lost work or destructed exergy per unit of time, $\mathrm{J} / \mathrm{s}$

$\eta \quad$ Thermodynamic efficiency, -

$\varsigma \quad$ Service efficiency improvement, - 


\section{References}

[1] Key World Energy Statistics, Technical Report, International Energy Agency, 2011.

[2] Directive 2012/27/EU of the European Parliament and of the Council of Energy Efficiency, 2012.

[3] T. E. Graedel, R. Barr, C. Chandler, T. Chase, J. Choi, L. Christoffersen, E. Friedlander, C. Henly, C. Jun, N. T. Nassar, D. Schechner, S. Warren, M. Yang, and C. Zhu, "Methodology of metal criticality determination," Environ. Sci. \& Techn., 46, 1063-1070, 2012.

[4] A. Valer, A. Valero. Thanatia: The Destiny of the Earth's Mineral Resources A Thermodynamic Cradle-toCradle Assessment, Imperial College Press. 2014.

[5] Appeal to UN and EU by 33 researchers, J. Int. Thermodynamics, 16, Sept. 2013

[6] N. Georgescu-Roegen, The entropy law and the economic process, Harvard University Press, Cambridge. 1971.

[7] M. J. Molina, F. S. Rowland, Stratospheric sink for chlorofluoromethanes: chlorine atom-catalysed destruction of ozone, Nature, 249, 810-812, 1974.

[8] J. Dewulf, H. Van Langenhove, E.J. Vandamme. Resource Technology - a challenge for scientists and engineers. Chem Technol Biotechnol., 85, 1299-1300, 2010 .

[9] J. Dewulf, H. Van Langenhove, J. Mulder, M.M.D. van den Berg, H.J. van der Kooi, J. de Swaan Arons. "Illustrations towards quantifying the sustainability of technology". Green Chemistry, 2, 108-114, 2000.

[10] Erkman S. "Industrial ecology: An historical view", Journal of Cleaner Production, 5, 1-10, 1997.

[11] S. Hellweg, L. Milà i Canals, "Emerging approaches, challenges and opportunities in life cycle assessment", Science, 344, 1109-1113, 2014.

[12] Online: Available

http://epp.eurostat.ec.europa.eu/portal/page/portal/europe 2

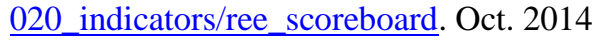

[13] Huysman S., Sala S., Mancini L., Ardente F., Matthieux F., Alvarenga R.A.F., De Meester S., Dewulf J. Towards a systematized framework for resource efficiency indicators, Submitted to Resources, Conservation and Recycling, 2014.

[14] J. Szargut, D.R. Morris, F.R. Steward. Exergy Analysis of Thermal, Chemical and Metallurgical Processes, Hemisphere, New York, 1988.

[15] J. Dewulf, H. Van Langenhove, B. Muys, S. Bruers, B.R. Bakshi, G. Grubb, D.M. Paulus, E. Sciubba. Exergy: Its Potential and Limitations. Environ. Sci. \& Techn., 42, 2221-2232, 2008

[16] A. Zvolinschi, S. Kjelstrup, O. Bolland, H. van der Kooi, "Exergy Sustainability Indicators as a Tool in Industrial Ecology: Application to Two Gas-Fired Combined Cycle Power Plants", J. Industrial Ecology, 11, 85-98, 2007.
[17] A. Zvolinschi, S. Kjelstrup, “A process maturity indicator for industrial ecology", J. Industrial Ecology, 12, 159-172, 2008.

[18] J. Humphrey, A. Siebert, "Separation technologies: an opportunity for energy savings", Chem. Eng. Progress, 88, 32-41, 1992

[19] G. de Koeijer, A. Røsjorde, S. Kjelstrup, «Distribution of heat exchange in optimum diabatic distillation columns», Energy, 29, 2425- 2440, 2004.

[20] A. Røsjorde, M. Nakaiwa, K. Huang, K. Iwakabe and S. Kjelstrup, «Second law analysis of an internal heat-integrated distillation column", In: Energy-Efficient, Cost-Effective and Environmentally-Sustainable Systems and Processes, Proceedings of ECOS 2004, Guanajuato, Mexico, July 7-9, ed. R. Rivero, L. Monroy, R. Pulido, G. Tsatsaronis, Vol. I, Instituto Mexicano del Petroleo, Mexico City, 107-115, 2004.

[21] S. Kjelstrup, D. Bedeaux, E. Johannessen, Nonequilibrium Thermodynamics for Engineers, World Scientific, Singapore, 2010.

[22] Y. Demirel, "Sustainable Operations for Distillation Columns”, Chem. Eng. Process Tech., 1, 1005, 2013.

[23] A. Valero, A. Valero, A. Martinez, "Inventory of the exergy resources on earth including its mineral capital", Energy, 35, 989-995, 2010.

[24] Huijbregts, M.A.J, Hellweg, S., Frischknecht, R., Hendriks, H,W.M., Hungerbühler, K., Hendriks, A.J., Cumulative energy demand as predictor for the environmental burden of commodity production, Environ. Sci. Technol., 44, 2189-2196, 2010.

[25] USDOE Industrial Technologies Program Chemical Bandwidth Study. Exergy Analysis: A Powerful Tool for Identifying Process Inefficiencies in the U.S. Chemical Industry. Summary Report December 2004. Study conducted for the U.S. Department of Energy by JVP International, Incorporated and Psage Research, LLC. 37 p., 2004.

[26] R.U. Ayres, L. Talens Peiro, G. Villalba Mendez. "Exergy Efficiency in Industry: Where Do We Stand?" Environ. Sci. and Techn., 45, 10634-10641, 2011.

[27] P.E. Brockway, J.R. Barrett, T.J. Foxon, J.K. Steinberger. "Divergence of Trends in US and UK Aggregate Exergy Efficiencies 1960-2010”, Environ. Sci. and Techn., 48, 9874-9881, 2014.

[28] D. Favrat, F. Marechal, O. Epelly «The challenge of introducing an exergy indicator in a local low on energy", Energy, 33, 130-136, 2008.[29] O. Ignatenko, A. van Schaik, M.A. Reuter. Exergy as a tool for evaluation of the resource efficiency of recycling systems. Minerals Engineering, 20, 862-874, 2007. 